\title{
SERGAMUMAS LYTIŠKAI PLINTANČIOMIS INFEKCIJOMIS VILNIAUS MIESTE 2009-2015 METAIS
}

\author{
Kęstutis Štaras ${ }^{2,1,3}$, Audronė Juodaitè-Račkauskiene் $\dot{e}^{3,1}$, Daiva Čepuraitėe \\ ${ }^{1} V_{S} I$ Centro poliklinika, ${ }^{2}$ Mykolo Romerio universitetas, \\ ${ }^{3}$ Vilniaus universiteto Medicinos fakultetas
}

Raktažodžiai: lytiškai plintančios infekcijos, Chlamydia trachomatis, Ureaplasma urealyticum, Mycoplasma genitalium, sexually transmitted deseases.

\begin{abstract}
Santrauka
Straipsnyje pateikiami 2009 - 2015 metų Vš Ċ Centro poliklinikoje vykdytos visuomenès sveikatos priemonès, finansuojamos Vilniaus miesto savivaldybès visuomenès sveikatos rèmimo specialiosios programos lëšomis „Lytiškai plintančių infekcijų profilaktika“ duomenys. Nustatyta, kad 2009 - 2015 m. didžioji dalis moterų (net 86,4 proc.) dẻl lytiškai plintančių infekcijų atvyko pasitikrinti profilaktiškai, ir tik 13,6 proc. moteru - turèdamos simptomatiką. Atlikti tyrimai rodo, kad iki $19 \mathrm{~m}$. amžiaus grupeje Mycoplasma genitalium infekcijos paplitimas yra žymiai didesnis negu $40-50 \mathrm{~m}$. amžiaus grupèje. Didžiausias sergamumas Chlamydia trachomatis lytiškai plintančia infekcija yra 20-29 m. amžiuje. Vertinant atliktų tyrimų rezultatus, nustatyta, kad amžiaus grupèse $20-29$ m. ir $30-39$ $\mathrm{m}$. Ureaplasma urealyticum infekcijos paplitimas yra rečiausias, tačiau $40-50 \mathrm{~m}$. amžiaus grupèje dažniausias iš visų lytiškai plintančių infekcijų tirtų tarp moteru.
\end{abstract}

\section{Ivadas}

Lytiniu keliu plintančios ligos ir jų prevencijos metodai iki šiol pasaulyje yra opi ir vis dar neišspręsta problema [7]. Kai kurios lytiškai plintančios infekcijos gali netureti simptomų, todèl jas tiksliai diagnozuoti galima tik specialiais tyrimais. Lytiškai plintančių infekcijų tyrimui atlikti imamas mėginys (paimama išskyrų) iš varpos, vaginos ar gimdos kaklelio, kartais iš burnos, išangès. Kai kurioms infekcijoms (pvz. sifilio, ŽIV ir kt.) išsiaiškinti imamas kraujas iš venos. Pradėtą gydymo kursą visada reikia pabaigti, nors susirgimo simptomai gali išnykti ir anksčiau. Susirgus ar gydymo metu privaloma vengti lytinių santykių, o po gydymo rekomenduojama pakartotinai atvykti pasitikrinti pas gydytoją.

Chlamydia trachomatis - labiausiai paplitusi bakterinè lytiškai plintanti infekcija. Pasaulio sveikatos organizacijos duomenimis, pasaulyje kasmet naujai chlamidine infekcija užsikrečia 100 milijonų žmonių. Didžiausią užsikrètusiųų dalį sudaro jaunesni nei 29 metų amžiaus lytiškai aktyvūs asmenys [1]. Norvegijos užkrečiamųų ligų centro duomenimis (Norwegian Surveillance System for Communicable Diseases (MSIS), nuo 1990 m. iki 2013 m. užsikrètusiųjų chlamidine infekcija skaičius padidèjo dvigubai (nuo 4 proc. iki 8 proc. tirtujų asmenų). Atlikti tyrimai parodè, kad moterys dažniau serga šia infekcija negu vyrai, taip pat didesnè tikimybė susirgti išlieka jau sirgus Chlamydia trachomatis anksčiau [13, 14]. Anglijoje 2010 - 2012 m. atlikto tyrimo metu paaiškejo, kad moterys $(3,1$ proc.) taip pat dažniau serga chlamidine infekcija negu vyrai (2.3 proc. tirtujų asmenų) [15]. Urogenitalinę chlamidiozę sukelia Chlamydia trachomatis rūšies D - K serotipai. Šia infekcija užsikrečiama per nesaugius lytinius (vagininius, oralinius ar analinius) santykius nuo infekuoto asmens, taip pat motina gali užkrèsti naujagimi gimdymo metu [2].

Lietuvoje Chlamydia trachomatis paplitimas gerokai viršija kai kurių Vakarų šalių rodiklius. Priežasčių yra ịvairių. Tai nepakankamas pacientų informuotumas apie lytiškai plintančias infekcijas bei apsaugą lytinių santykių metu; nepasitikèjimas ar baimė kreiptis ị savo šeimos gydytoją ar gydytojus specialistus - dermatovenerologą, urologą, ginekologą; nepasitikejjimas valstybinès įstaigos laboratorine tarnyba, palyginti su privačia; netobula atvejų pranešimo epidemiologinei tarnybai sistema [3].

Besimptomès infekcijos yra klastingos dèl ilgalaikių pasekmių. Chlamydia trachomatis negydyta infekcija sukelia mažojo dubens uždegiminę ligą, o jos pasekmè - negimdinis néštumas arba nevaisingumas. Be to, jauna moteris gali ilgą laiką platinti infekciją, perduodama ją partneriams. Ši 
infekcija - didelè visuomenès problema, ypač dèl moterims skirtų sveikatos priežiūros išlaidų dẻl ypač rimtų ligų pasekmių, pavyzdžiui, dubens uždegiminès ligos (PID), kiaušintakių faktoriaus nevaisingumo, lètinio dubens skausmo ir negimdinio něštumo. Nèra jokių ịrodymų, kad natūralus imunitetas gali suteikti visišką ir ilgalaikę apsaugą, todèl vakcinacija yra būtina, siekiant išvengti lètinès patologijos ir komplikacijų. Vakcinos sukeltas dalinis imunitetas, apsaugantis nuo lytinių takų infekcijos ir uždegimo - ekonomiškai efektyvus būdas, palyginti su dabartinèmis gydymo metodikomis [4]. Ureaplasma urealyticum yra labiausiai paplitusi lytiškai plintanti infekcija tarp vyrų ir moterų, sergančių urogenitalinès infekcijos ligomis. Neatidèliotina diagnostika ir tinkamas medikamentinis gydymas yra viena iš būtinų sąlygų, kad būtų išvengta ilgalaikių Ureaplazma infekcijos komplikacijų. Be lytinių takų infekcijų ir nevaisingumo, Ureaplazma taip pat yra susijusi su nepageidaujamomis néštumo komplikacijomis ir ịvairiomis naujagimių ligomis (pvz. lètinè plaučių liga ar neišnešiotų naujagimių retinopatija). Ši infekcija amnione gamina citokinus, kurie skatina priešlaikini gimdymą [5].

Irodyta, kad moterų rizika susirgti lytiškai plintančiomis infekcijomis yra statistiškai proporcinga moterų lytiniam aktyvumui. Todẻl, ieškant galimybių sumažinti lytiškai plintančių infekcijų riziką, reikalinga informacija apie moterų lytinį aktyvumą [6].

Ivairiose šalyse atliekami tyrimai rodo, kad žmogaus papilomos virusas labai dažnai aptinkamas jaunoms moterims ir rodo, kad Chlamydia trachomatis -Hsp60 geno ekspresija gali skatinti žmogaus papilomos viruso infekciją [8].

Šiuo metu žinoma daugiau kaip 120 mikoplazmų rūšių. Žmogaus organizme jų aptinkama iki 20. Dauguma genitalijų mikoplazmų yra fakultatyvūs anaerobai. Lyties organuose aptiktos tik septynios iš jau žinomų mikoplazmų rūšių: $M$. hominis, $M$. genitalium, $M$. fermentans, $M$. penetrans, M. pneumoniae, M. primatum ir M. spermatofhilum. Ureaplazma nèra atskira bakterijų rūšis. Tai mikoplazmos, hidrolizuojančios šlapalą (urea) [11, 12].

Mikoplazmos kolonizuoja moters urogenitalinę sistemą ir pastaruoju metu vis dažniau siejama su kai kuriais reprodukcinès sistemos patologiniais pokyčiais [9]. Dauguma patogeninių mikoplazmų pažeidžia kvejpavimo takų arba urogenitalinių organų epitelio ląsteles. Infekcija retai atsiranda žaibiškai, dažniau jos eiga lètinè [10].

Tyrimo respondentai buvo suskirstyti ị keturias amžiaus kvartiles: iki 19 m., $20-29$ m., $30-39$ m. ir $40-50$ m. Tyrimo metu surinkti duomenys buvo klasifikuojami, lygina$\mathrm{mi}$ ir apdorojami. Statistinis duomenų apdorojimas atliktas SPSS v.19 programiniu paketu.

Statistinių-koreliacinių ryšių stiprumui (kintamiesiems be skirstinio normalumo prielaidos) bei krypčiai nustatyti pasirinktas neparametrinis Spearmen'o koreliacijos koeficientas (rho), kai p $<0,05$.

Tyrimo tikslas - išsiaiškinti sergamumą lytiškai plintančiomis infekcijomis Vilniaus mieste tarp $18-50 \mathrm{~m}$. amžiaus moterų.

\section{Darbo objektas ir metodas}

2009 - $2015 \mathrm{~m}$. vykdomų visuomenès sveikatos priemonių, finansuojamų Vilniaus miesto savivaldybès visuomenès sveikatos rèmimo specialiosios programos léšomis „Lytiškai plintančių infekcijų profilaktika“ VšĮ Centro po-

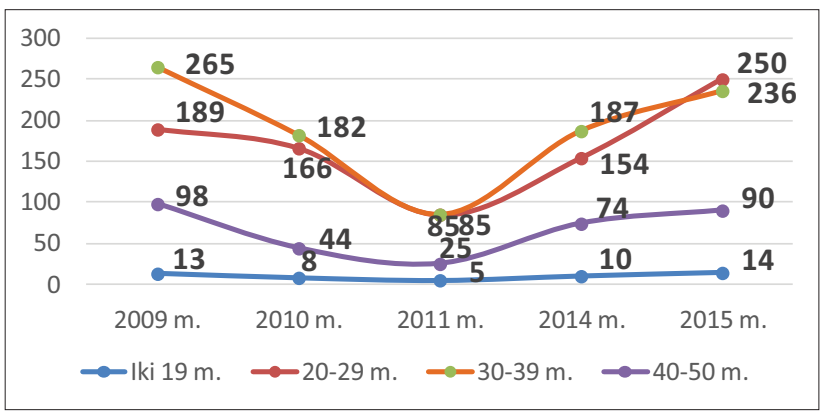

1 pav. 2009 - 2015 metų ištirtų moterų skaičius

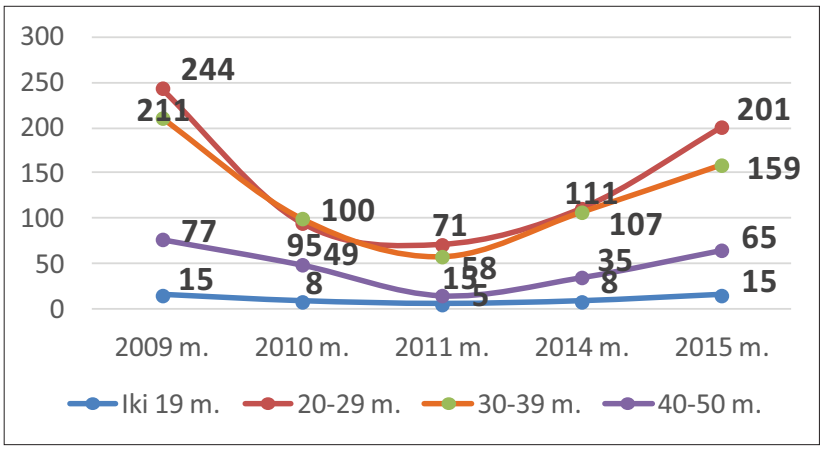

2 pav. Rastų infekcijų atvejų skaičiaus kaita 2009 - 2015 metais

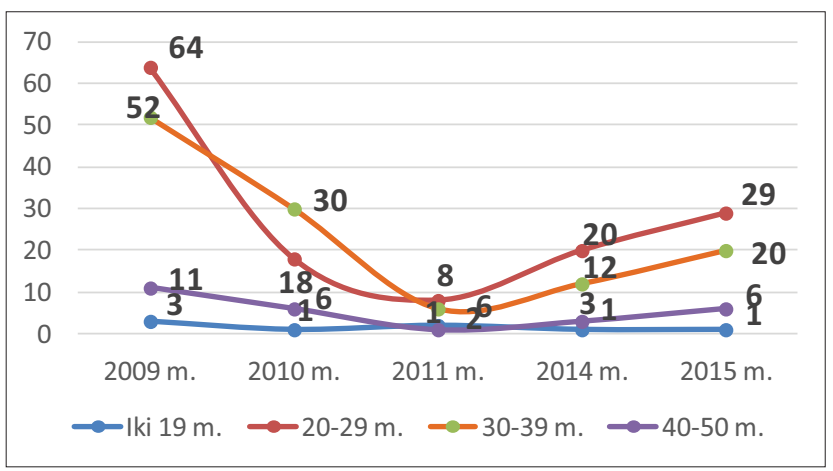

3 pav. Chlamydia trachomatis rastų infekcijų atvejai 2009 - 2015 metais 
liklinikoje metu, buvo analizuojami laboratorinių tyrimų duomenys.

Šios programos tikslas buvo anksti diagnozuoti lytiniu keliu plintančias infekcijas, skirti tinkamą gydymą ir siekti sumažinti lytiškai plintančių ligų paplitimą (toliau - LPL) bei jų sukeliamas komplikacijas.

Uždaviniai:

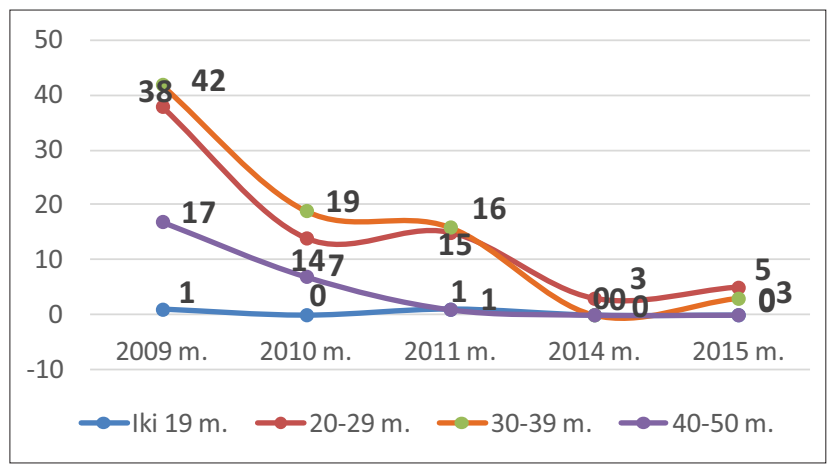

4 pav. Mycoplasma genitalium rastų infekcijų atvejai 2009 2015 metais

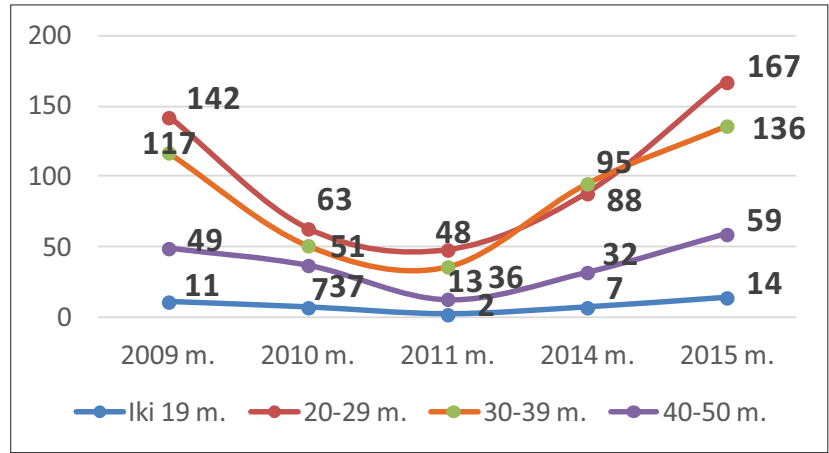

5 pav. Ureaplasma urealyticum rasti infekcijos atvejai $2009-$ 2015 metais

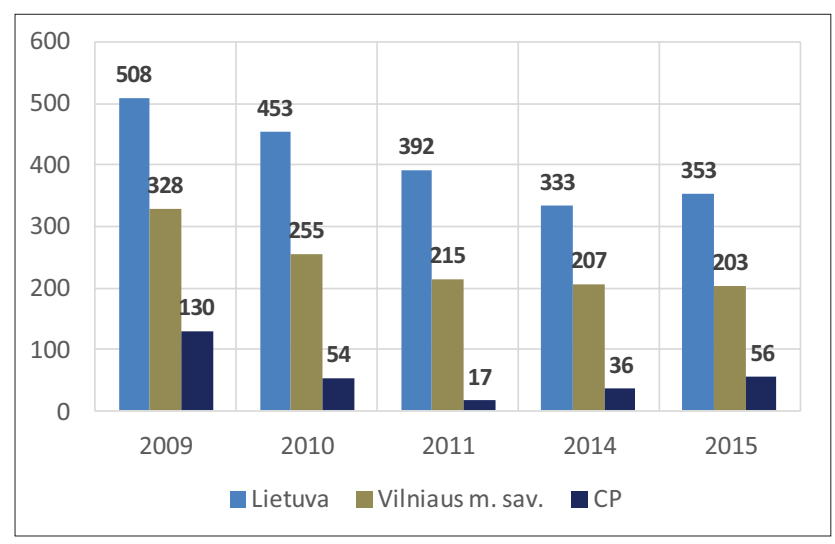

6 pav. Chlamydia trachomatis rastų infekcijos atvejų 2009 - 2015 metais palyginimas Lietuvos, Vilniaus miesto ir Všt Centro poliklinikos mastu
1. Lytiniu keliu plintančių ligų profilaktika.

2. Sergamumo LPL priklausomybė nuo amžiaus.

3. Ištyrimas ir gydymas dèl lytiškai plintančių infekcijų.

4. Pacientų švietimas dèl LPL sergamumo.

$2009-2015$ m. Vš Centro poliklinikoje dèl LPL ištirta 2190 moterų. Iki 19 m. ištirta 50, 20 - 29 m. - 844, 30 - 39 m. -955 ir $40-50$ m. -331 moteris. 2009 m. ištirta 565, 2010 m. - 400, 2011 m. - 200, 2014 m. - 425, o 2015 m. net 600 moteru [ 1 pav.].

86,4 proc. moterų dèl lytiškai plintančiu infekcijų atvyko pasitikrinti profilaktiškai, 13,6 proc. - turèdamos simptomatiką.

$2009-2015 \mathrm{~m}$. iš 2190 ištirtų moteru rasta 1649 infekcijų. Iki $19 \mathrm{~m}$. rasta 51, $20-29 \mathrm{~m}$. $-722,30-39 \mathrm{~m}$. 635 ir $40-50$ m. -241 infekcija. 2009 m. rasta 547, 2010 m. $-252,2011$ m. $-149,2014$ m. -261 , o 2015 m. -440 infekcijų [2 pav.].

2009 - 2015 m. dažniausiai rasta Ureaplazma urealyticum infekcija (2009 m. - 319, 2010 m. - 158, 2011 m. - 99, 2014 m. - 222 ir 2015 m. - net 376 atvejų). Tuo pačiu laikotarpiu rečiausiai buvo aptinkama mikoplazma genitalium infekcija (2009 m. - 98, 2010 m. - 40, 2011 m. - 33, 2014 m. -3 ir 2015 m. -8 atvejai) [1 lentelè].

Svarbu atkreipti dèmesị i tai, kad Chlamydia trachomatis infekcijos atvejų daugiausia rasta $2009 \mathrm{~m}$. tarp įvairaus amžiaus moterų. Iki $19 \mathrm{~m}$. -3 atvejai (37,5 proc.), $20-29$ m. amžiaus - 64 atvejai ( 46,05 proc.), $30-39 \mathrm{~m}$. amžiaus - 52 atvejai $(43,34$ proc.) ir 40 - $50 \mathrm{~m}$. amžiaus - 11 atvejų (42,31 proc.). Spearmen'o koreliacijos koeficientas -0.1, $\mathrm{p}=0.873$ rodo, kad didžiausia tikimybė moterims susirgti Chlamydia trachomatis lytiškai plintančia infekcija yra 20 - 29 m. amžiuje [3 pav.].

Akcentuotina tai, kad Mycoplasma genitalium infekcijos atvejų taip pat daugiausia rasta $2009 \mathrm{~m}$. tarp ịvairaus amžiaus moterų. Iki $19 \mathrm{~m}$. -1 atvejis (50 proc.), $20-29 \mathrm{~m}$. amžiaus - 38 atvejai (50,67 proc.), $30-39 \mathrm{~m}$. amžiaus -42 atvejai $(52,5$ proc.) ir $40-50 \mathrm{~m}$. amžiaus -17 atveju ( 68 proc.). Tačiau šios infekcijos atvejų kasmet palaipsniui mažejo. Atlikti tyrimai įrodo, kad iki $19 \mathrm{~m}$. amžiaus grupejje (Spearmen'o koreliacijos koeficientas - 0,577, p =0,308) Mycoplasma genitalium infekcijos paplitimo tikimybė yra žymiai didesnè negu $40-50 \mathrm{~m}$. amžiaus grupejje (Spearmen'o koreliacijos koeficientas $-0,975, p=0,005$ ) [4 pav.].

Laboratorinių tyrimų duomenų analizé parodè, kad Ureaplasma urealyticum infekcijos atvejų kasmet vis daugeja. Ši infekcija ypač paplitusi tarp $20-29 \mathrm{~m}$. ir $30-$ $39 \mathrm{~m}$. amžiaus moterų. $2009 \mathrm{~m}$. aptikta 319 atvejų $(27,18$ proc.), 2010 m. - 158 atvejai (13,46 proc.), 2011 m. - 99 atvejai (8,44 proc.), $2014 \mathrm{~m}$. - 222 atvejai (18,91 proc.), o 
2015 m. - net 376 atvejai (32,03 proc.). Vertinant atliktų tyrimų rezultatus, nustatyta, kad amžiaus grupèse $20-29 \mathrm{~m}$. ir $30-39 \mathrm{~m}$. (Spearmen'o koreliacijos koeficientas $0,3, \mathrm{p}=0,624)$ Ureaplasma urealyticum infekcijos paplitimas yra rečiausias, o $40-50 \mathrm{~m}$. amžiaus grupejje (Spearmen'o koreliacijos koeficientas - $0,1, p=0,873)$ - dažniausias paplitimas [5 pav.].

Atliktu tyrimų rezultatai parode, kad $2009 \mathrm{~m}$. išgydytos 424 (100 proc.) moterys, $2010 \mathrm{~m}$. -247 (100 proc.), 2011 m. - 130 (100 proc.), 2014 m. 244 (100 proc.), 2015 m. -393 (100 proc.) moterys.

\section{Išvados}

1. Nustatyta, kad 2009 - 2015 m. didžioji dalis moterų (net 86,4 proc.) dèl lytiškai plintančių infekcijų atvyko pasitikrinti profilaktiškai, ir tik 13,6 proc. moterų - turédamos simptomatiką.

2. Atlikti tyrimai įrodo, kad iki $19 \mathrm{~m}$. amžiaus grupejje Mycoplasma genitalium infekcijos paplitimo tikimybė yra žymiai didesnè negu $40-50 \mathrm{~m}$. amžiaus grupejje. Didžiausia tikimybė moterims susirgti Chlamydia trachomatis lytiškai plintančia infekcija yra $20-29$ m. amžiuje. Vertinant atliktu tyrimų rezultatus, nustatyta, kad amžiaus grupèse $20-29 \mathrm{~m}$. ir $30-39 \mathrm{~m}$. Ureaplasma urealyticum infekcijos paplitimas yra rečiausias, o $40-50 \mathrm{~m}$. amžiaus grupejje - dažniausias paplitimas.

3. 2009 - 2015 m. atliktų tyrimų rezultatai rodo, kad visos pacientes, kurioms rasta Chlamydia trahomatis, Mycoplasma genitalium ar Ureaplasma urealyticum infekcijų 100 proc. išgydytos.

\section{Rekomendacijos}

1. Lytiškai plintančių infekcijų tyrimus siūlome kompensuoti Privalomojo sveikatos draudimo fondo biudžeto lèšomis, kad šeimos gydytojai ir gydytojai specialistai galètų juos skirti pacientems nemokamai. Tik tuomet būtų galima žymiai greičiau sumažinti šių infekcijų paplitimo galimybes bei taikyti tikslesnes bei veiksmingas prevencijos ir gydymo priemones.

2. Aktyvinti pacientų informuotumą apie lytiškai plintančias infekcijas bei apsaugą lytinių santykių metu, pradedant mokymus ugdymo įstaigose.

\section{Literatūra}

1. WHO. Figure 4. Estimated new cases of chlamydial infections among adults, 1999. Available from: www. who.int/docstore/hiv/GRSTI/pdf/figure04.pdf, 2006.
1 lentelè. 2009 - 2015 metais rasti infekcijos atvejai pagal sukèleją

\begin{tabular}{|l|c|c|c|c|c|}
\hline \multirow{2}{*}{ Infekcijos } & \multicolumn{5}{|c|}{ Amžiaus grupès } \\
\cline { 2 - 6 } & Iki 19 m. & $\mathbf{2 0 - 2 9} \mathbf{~ m . ~}$ & $\mathbf{3 0 - 3 9} \mathbf{~ m . ~}$ & $\mathbf{4 0 - 5 0 ~ m . ~}$ & Iš viso \\
\hline $\begin{array}{l}\text { Chlamydia } \\
\text { trachomatis }\end{array}$ & 1 & 29 & 20 & 6 & 56 \\
\hline $\begin{array}{l}\text { Myco- } \\
\text { plasma ge- } \\
\text { nitalium }\end{array}$ & 14 & 167 & 136 & 59 & 376 \\
\hline $\begin{array}{l}\text { Ureaplasma } \\
\text { urealyticum }\end{array}$ & 14 & 3 & & 8 \\
\hline
\end{tabular}

2 lentelè. Chlamydia trachomatis rastų infekcijų atvejai 2009-2015 metais

\begin{tabular}{|l|l|l|l|l|}
\hline $\begin{array}{l}\text { Spearmen'o } \\
\text { rho }\end{array}$ & $\begin{array}{l}-0,671 \\
\mathrm{p}=0,215\end{array}$ & $\begin{array}{l}-0,1 \\
\mathrm{p}=0,873\end{array}$ & $\begin{array}{l}-0,6 \\
\mathrm{p}=0,285\end{array}$ & $\begin{array}{l}-0,462 \\
\mathrm{p}=0,434\end{array}$ \\
\hline $\begin{array}{l}\text { Stjudent'o } \\
\text { testas }\end{array}$ & $\begin{array}{l}1,6 \\
\mathrm{p}=0,016\end{array}$ & $\begin{array}{l}27,8 \\
\mathrm{p}=0,045\end{array}$ & $\begin{array}{l}24 \\
\mathrm{p}=0,041\end{array}$ & $\begin{array}{l}5,4 \\
\mathrm{p}=0,033\end{array}$ \\
\hline
\end{tabular}

3 lentelè. Mycoplasma genitalium rastų infekcijų atvejai 2009-2015 metais

\begin{tabular}{|l|l|l|l|l|}
\hline $\begin{array}{l}\text { Spearmen'o } \\
\text { rho }\end{array}$ & $\begin{array}{l}-0,577 \\
\mathrm{p}=0,308\end{array}$ & $\begin{array}{l}-0,8 \\
\mathrm{p}=0,104\end{array}$ & $\begin{array}{l}-0,9 \\
\mathrm{p}=0,037\end{array}$ & $\begin{array}{l}-0,975 \\
\mathrm{p}=0,005\end{array}$ \\
\hline $\begin{array}{l}\text { Stjudent'o } \\
\text { testas }\end{array}$ & $\begin{array}{l}0,4 \\
\mathrm{p}=0,178\end{array}$ & $\begin{array}{l}15 \\
\mathrm{p}=0,073\end{array}$ & $\begin{array}{l}16 \\
\mathrm{p}=0,098\end{array}$ & $\begin{array}{l}5 \\
\mathrm{p}=0,201\end{array}$ \\
\hline
\end{tabular}

4 lentelè. Ureaplasma urealyticum rasti infekcijos atvejai 2009-2015 metais

\begin{tabular}{|l|l|l|l|l|}
\hline $\begin{array}{l}\text { Spearmen'o } \\
\text { rho }\end{array}$ & $\begin{array}{l}0,205 \\
\mathrm{p}=0,0741\end{array}$ & $\begin{array}{l}0,3 \\
\mathrm{p}=0,624\end{array}$ & $\begin{array}{l}0,3 \\
\mathrm{p}=0,624\end{array}$ & $\begin{array}{l}0,1 \\
\mathrm{p}=0,873\end{array}$ \\
\hline $\begin{array}{l}\text { Stjudent'o } \\
\text { testas }\end{array}$ & $\begin{array}{l}8,2 \\
\mathrm{p}=0,016\end{array}$ & $\begin{array}{l}101,6 \\
0,011\end{array}$ & $\begin{array}{l}87 \\
\mathrm{p}=0,01\end{array}$ & $\begin{array}{l}38 \\
\mathrm{p}=0,008\end{array}$ \\
\hline
\end{tabular}

2. Auškalnis S., Jasinauskaitè D. Šlapimo ir lyties organų chlamidinė infekcija. Lietuvos bendrosios praktikos gydytojas, 2010; 14:4.

3. Domeika M. ir kt. Chlamydia trachomatis infekcijos laboratorinė diagnostika. Laboratorinè medicina. Mokomoji knyga. 2010;3(47): 147.

4. Poston TB, Darville T. Chlamydia trachomatis: protective adaptive responses and prospects for a vaccine. 2016 Apr 1 .

5. Kokkayil P, Dhawan B. Indian J Med Microbiol. 2015 AprJun;33(2):205-14. doi: 10.4103/0255-0857.154850. Ureaplasma: current perspectives.

http://dx.doi.org/10.4103/0255-0857.154850

6. Navarro-Cremades F, Palazón-Bru A, Marhuenda-Amorós D, TomásRodríguez MI, Antón-Ruiz F, Belda-Iba-ez J, Luis Montejo A, GilGuillén PeerJ VF. Sexual behaviour and risk of sexually transmitted infections in young female healthcare students in Spain. 2016 Feb 25;4:e1699. doi: 10.7717/peerj.1699. eCollection 2016. http://dx.doi.org/10.7717/peerj.1699

7. Seidman D, Hemmerling A, Smith-McCune K. emerging technologies 
to prevent pregnancy and sexually transmitted infections in women. Semin Reprod Med 2016 Mar.

8. HPV genotypes distribution in Chlamydia trachomatis coinfection in a large cohort of women from North-East Italy. Seraceni S, Campisciano G, Contini C, Comar M. J Med Microbiol 2016 Mar 3.

9. Jarienė K., Tvarijonavičienė E. Mikoplazmų reikšmė moters reprodukcinei sveikatai. Lietuvos akušerija ir ginekologija, 2012; 15(1):55-63.

10. Razina S, Yogev D., Naot Y. Molecular biology and pathogenicity of mycoplasmas. Microbiol Mol Biol Rev 1998; 46(3):1094-156.

11. Hartmann M. Genital mycoplasmas. J Dtsch Dermatol Ges 2009; 7(4):371-7. http://dx.doi.org/10.1111/j.1610-0387.2008.06965.x

12. Taylor-Robinson D. The role of mycolpasmas in pregnancy outcome. Best Pract Res Clin Obstet Gynaecol 2007; 21(3):42538 .

http://dx.doi.org/10.1016/j.bpobgyn.2007.01.011

13. Kløvstad H, Aavitsland P. Denominators count: supplementing surveillance data for genital Chlamydia trachomatis infection with testing data, Norway, 2007 to 2013. Norwegian Institute of Public Health, Department of Infectious Disease Epidemiology, Oslo, Norway, 2015;20(36).

14. Kløvstad H, Grjibovski A, Aavitsland P. Population based study of genital Chlamydia trachomatis prevalence and associated factors in Norway: a cross sectional study. Norwegian Institute of Public Health, Oslo, Norway. hilde.klovstad@fhi.no. 2012 Jul 2;12:150.

15. Woodhall SC, Soldan K, Sonnenberg P, Mercer CH, Clifton S, Saunders P, da Silva F, Alexander S, Wellings K, Tanton C, Field N, Copas AJ, Ison CA, Johnson AM. Is chlamydia screening and testing in Britain reaching young adults at risk of infection? Findings from the third National Survey of Sexual Attitudes and Lifestyles (Natsal-3). 2016 May; 92(3):218-27. doi: 10.1136/sextrans-2015-052013. Epub 2015 Aug 19.

http://dx.doi.org/10.1136/sextrans-2015-052013

\section{PREVALENCE OF SEXUALLY TRANSMITTED INFECTIONS IN VILNIUS FROM 2009 TO 2015}

K. Štaras, A. Juodaitè-Račkauskienė, D. Čepuraitė

Key words: sexually transmitted deseases, Chlamydia trachomatis, Ureaplasma urealyticum, Mycoplasma genitalium.

Summary

The aim of the research is to find out the morbidity of sexually transmitted infections in Vilnius city among women aged $18-50$.

The article presents $2009-2015$ public health measure's, financed by the Vilnius city municipality public health support funds of the special programme "Prevention of Sexually Transmitted Infections", Vilnius Centro Outpatient Clinic laboratory findings. It was found that the 2009 - 2015 year. the majority of women (86.4 percent.) for sexually transmitted infections came undergo prophylactic, and only 13.6 percent women - bearing symptoms. Studies show that up to 19 years. in the age group of Mycoplasma genitalium infection is much higher than 40 - 50 years. age group. The highest incidence of chlamydia trachomatis sexually transmitted infection of 20 - 29 years. century. The evaluation results of the investigations, it was found that the age group 20 - 29 years and 30 - 39 years. Ureaplasma urealyticum infection is the rarest, but 40 - $50 \mathrm{~m}$. age group - the most common of all sexually transmitted infections among women surveyed.

Correspondence to: daiva.cepuraite@gmail.com

Gauta 2016-10-18 